\title{
Implementation of AD8232 ECG Signal Classification Using Peak Detection Method For Determining RST Point
}

\author{
${ }^{1}$ Martin Clinton Tosima Manullang, ${ }^{2}$ Jonathan Eprilio Soaduon Simanjuntak, ${ }^{3}$ Ahmad Luky Ramdani \\ 1,2,3 Departement of Informatics Engineering, Institut Teknologi Sumatera \\ Email: ${ }^{1}$ martin.manullang@if.itera.ac.id, ${ }^{2}$ jonathaneprilio@gmail.com, ${ }^{3}$ ahmadluky@if.itera.ac.id
}

\begin{tabular}{l}
\hline \hline Article Info \\
\hline Article history: \\
Received Aug $05^{\text {th }}, 2019$ \\
Revised Aug $16^{\text {th }}, 2019$ \\
Accepted Sep $14^{\text {th }}, 2019$ \\
\\
\hline Keyword: \\
Electrocardiograph \\
AD8232 \\
Arduino \\
PQRST Signal \\
Heart Attack \\
\hline
\end{tabular}

\begin{abstract}
The medical world, especially those related to diseases and management of the heart uses ECG as a measurement tool. ECG has important points determined based on predetermined characteristics. The point is PQRST, where three of them are used as research objects in this paper. AD8232 is used as a research medium where the RST points must be determined in the AD8232 plot results by first determining the $\mathrm{R}$ points based on the highest peak. The results obtained were satisfactory wherein from 10 ECG graphic samples, 9 of them obtained RST point measurements which tended to be similar to conventional ECG measurements using millimeter paper as plotting media. Accuracy values reaching more than $90 \%$ indicate the reliability of the implementation results.
\end{abstract}

Copyright @ 2019 Puzzle Research Data Technology

\section{Corresponding Author:}

Martin Clinton Tosima Manullang,

Departement of Informatics Engineering,

Institut Teknologi Sumatera,

Jalan Terusan Ryacudu, Way Hui, Kecamatan Jati Agung, Lampung Selatan 35365.

Email: martin.manullang@if.itera.ac.id

DOI: http://dx.doi.org/10.24014/ijaidm.v2i2.7593

\section{INTRODUCTION}

The medical world, especially the treatment and treatment of heart disease today has used a lot of equipment that has acquired analog data to make scientific measurements of changes and illness experienced by patients, one of those equipments is electrocardiogram. An electrocardiogram (ECG) is used to detect heart electrical signals which are an early indicator of abnormalities and diseases in heart, such as heart attack known as myocardial infarction, arrythmia, tachycardia, atrial fibriliation, etc.

One of the ECGs that is the focus of research is AD8232 where the ECG is an additional module for arduino microcontroller devices. The AD8232 module consists of 2 main components, the control board and electrode pins. The output of this tool will produce a decimal value that is read using a personal computar. The digital value when plotted in a graph will show a pattern of repetition, hereinafter known as a PQRST signal in the medical terms.

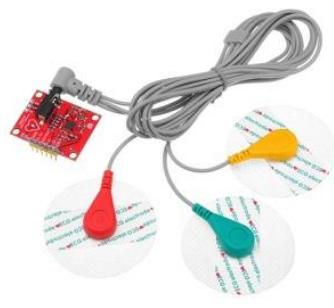

Figure 1. AD8232 Arduino Module

Signals from those three electrodes will produce a graph that has hills and valleys as a representation of the heart's electricity. The signal graph is divided into 5 parts, namely PQRST. Each of these parts represents 
the process of the heart beat so that through the PQRST graph the abnormalities and disorders can be identified. PQRST graphic form can be seen from figure 2.

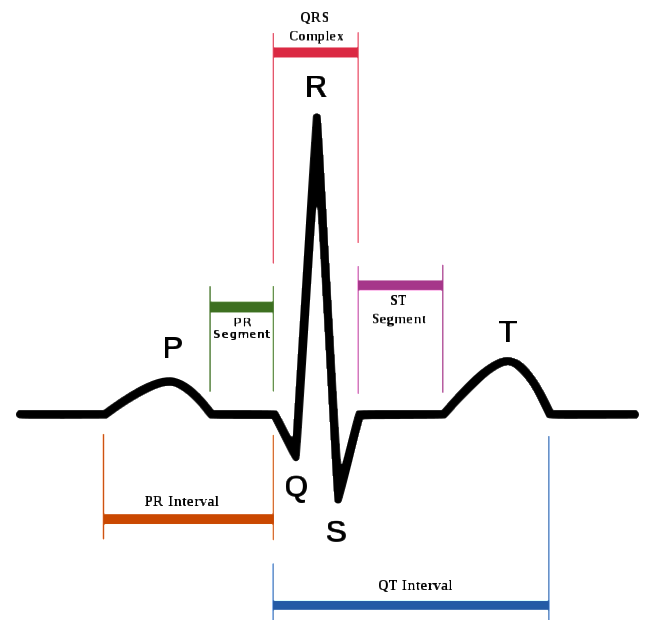

Figure 2. PQRST Graph

$\mathrm{P}$ waves occur due to the depolarization process. Depolarization is the process by which the heart contracts and produces atrial olarization contractions (the heart contracts) which causes contraction of the atria from the atrialis sinus to the ventricular atrio nodules. The next section is the PR Segment. This section is the time from the beginning of atrial contraction to the beginning of ventricular contraction. Next is the QRS complex. This part is the result of depolarization in the ventricles. QRS complex consists of several small parts [1].

Part $\mathrm{Q}$ is the first negative deflection, is interventricular septum depolarization activated from left to right, normal duration (except leads III and aVR) is less than 0.04 seconds and the height is less than one third the height of the $\mathrm{R}$ wave at the relevant leads. $\mathrm{R}$ wave is the highest wave and is often used as a reference to determine the average heart rate (heart rate). The end of the atria contraction and the beginning of ventricular contractions give rise to the $\mathrm{R}$ wave. The $\mathrm{S}$ section is the first negative deflection after the second $\mathrm{R}$. Deflection is called the $S$ wave. In general, the QRS complex has the following characteristics [1].

The $\mathrm{T}$ wave is ventricular repolarization, usually at less than $5 \mathrm{~mm}$ in the extremity leads or $10 \mathrm{~mm}$ in the precordial leads. T waves can be positive, negative, or biphasic. The ST segment is an early sign of left and right ventricular repolarization. The meeting point between the end of the QRS complex and the beginning of the ST segment is called the J point. If the J point is below the isoelectric line it is called the $\mathrm{J}$ point depression and if it is above the isoelectric line it is called the $\mathbf{J}$ point elevation [1].

The output data is time series data with the amount that reaches hundreds of data in one second. These data cannot be a reference to heart conditions and abnormalities if they are not classified in several signal points previously known as PQRST. In this data, the PQRST point must be determined so that the length and height of each point can be measured to determine the abnormality or disease suffered. This becomes a problem and a challenge where there must be a method or algorithm that is able to determine the location of PQRST points based on existing features. In this study, determining the point is limited only to determine the RST point because the three segments are used as a reference for several main measurements, such as average heart rate, heart attack (myocardial infarction), arrythmia, and other main symptomps [7].

\section{RESEARCH METHOD}

\subsection{Schematic Design}

To solve the above problems and implement and test the proposed method, it is necessary to design the hardware used as the object of research, in this case using an Arduino Uno board and ECG Module AD8232. Several previous studies have shown the level of accuracy and excellence offered by Arduino Uno with AD8232 as an ECG. The results of these tools are quite good in representing ECG signal measurements that are in accordance with medical standards. There have also been many studies comparing AD8232 output with ECG used in hospitals and emergency departments. Hardware design that used in this research can be seen from figure 3 . 


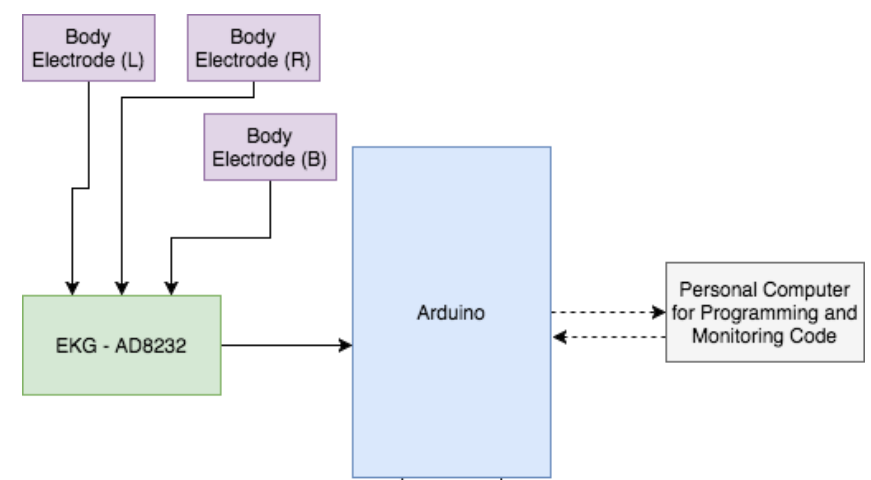

Figure 3. Hardware Schematic Design

To be able to display and plot a PQRST graphic, a software named processing is used. Processing is additional software developed for Arduino as a graphical interface for developers to be able to display the output of the serial monitor in a graphic.

The type of electrode pins used are gel electrodes. In addition to gel electrodes, in general patients can also use pin-type electrodes to record heart activity but pin-type electrodes have a lower level of sensitivity than gel electrodes that are attached to the body. To connect AD8232 with body electrodes, a cable with a $3.5 \mathrm{~mm}$ connector such as an audio connector is often found on smartphones. A hardware implementation can be shown on figure 4 .

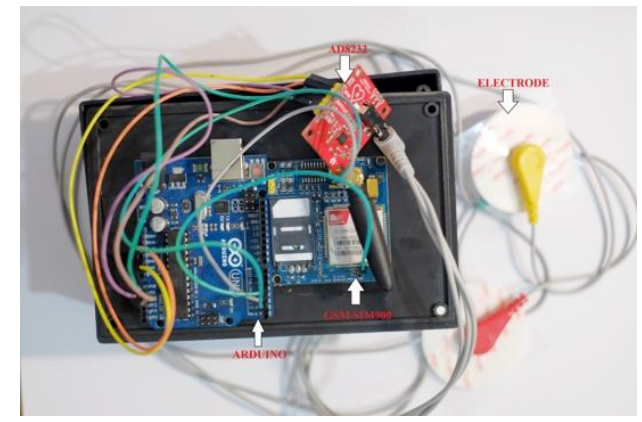

Figure 4. Hardware Implementation

\subsection{Software Design}

To determine the PQRST, a peak detection method is used as a first step filtering to define the R peak based on the PQRST theory. Because this study uses Arduino Uno with an Analog to Digital Converter resolution of 10bit, the recorded ECG range will range from 0 to 1023. A peak detection method is comparing each time series data and storing the largest number as a latest peak.. This latest peak will be compared with other time series data to achieve a new peak value. The initial step is to check whether the data is rising according to the baseline.

DataRising $=$ (data $>$ Baseline);

Data is considered up or down if data is up / down if the difference between data is $3 \%$ of height $(\mathrm{S}$ Baseline). Each change in data is recorded as the value of the change and the value of the increase and decrease. int difference $=$ (Baseline - DataSensorMinAverage_last)*2/100;

if (DataRising $!=$ DataRising_last \&\& (abs (data-Basēline) $>$ difference) $)\{$

if ( DataRising $==$ true ) \{

DataSensorMin_last $=$ DataSensorMin;

DataSensorMin = Baseline;

\}else \{

DataSensorMax_last = DataSensorMax;

DataSensorMax ${ }^{-}=$Baseline;

\}

Changestate++;

DataRising_last $=$ DataRising;

\} else \{ 
The first decrease in a signal cycle will be point $\mathrm{R}$. The first increase after point $\mathrm{R}$ is defined as point $\mathrm{S}$ until the next decrease is categorized as ST segment. In this study also calculated the distance between R which is used as a measurement of the average heart rate per minute. How to calculate it is quite easy, just by comparing the values between the peak $\mathrm{R}$ and calculating it with the formula below.

$$
\text { Heart Rate }=\frac{60000 \mathrm{~ms}}{R \text { end }- \text { R start }}
$$

By using the formula above repeatedly, we obtain an average heart rate per minute and can be stored in a container variable.

\subsection{Test Scenario}

The testing scheme used is to acquire real heart graphic data from 10 people and then compare the outputs with the results of the medical ECG plotting and ask for medical staff considerations in measuring the quality of PQRST point determination. The 10 people were chosen randomly without criteria from their fellow researchers in the writer's environment where the author himself did not know the history of the disease from the 10 people. Keep in mind that each person has a unique form of ECG signals and different length graphic characteristics.

\section{RESULTS AND ANALYSIS}

After being tested, the measurement results using AD8232 were compared with a medical standard ECG type Cardimax ECG type - Fukuda Denshi. This is an ECG with 10 electrodes and uses millimeter paper as a plot media. This picture is one example of 10 other graphs. The patient included in the example is the author himself. During the test, both of the measurement tools (AD8232 and Cardimax ECG) were installed on the same body at the same time to comparing and plotting the graph.

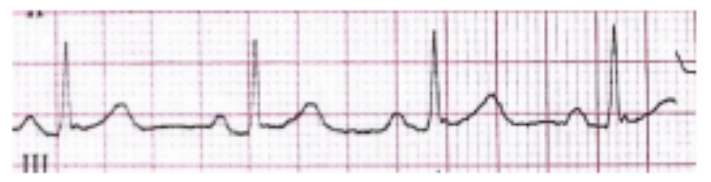

Figure 5. A Conventional ECG Plot Result

The next graph below is the measurement results using AD8232 by determining the RST point and measuring the distance between $\mathrm{R}$ and other variables.

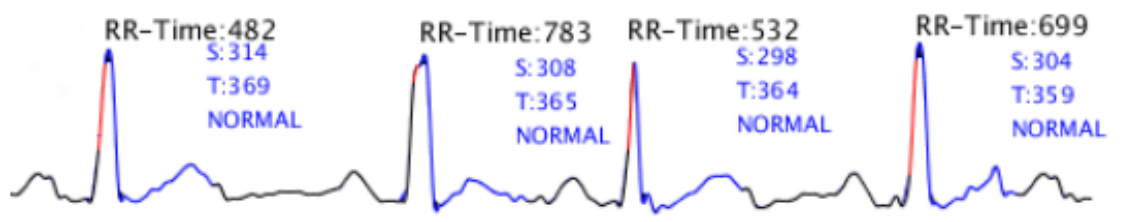

Figure 6. The RST Plotted on Graph Using AD8232

In further measurements, the distance on millimeter paper is compared with a weighted comparison to the AD8232 output graph and the following calculation is made.

Table 1. Line Analysis From Both Graph

\begin{tabular}{cccccc}
\hline $\begin{array}{c}\text { t-peak } \\
\text { value }\end{array}$ & $\begin{array}{c}\text { Initial value of } \\
\text { the system }\end{array}$ & $\begin{array}{c}\text { Final value T } \\
\text { on the system }\end{array}$ & $\begin{array}{c}\text { High peak ST segment } \\
\text { using the system }(\mathrm{T}-\mathrm{S})\end{array}$ & $\begin{array}{c}\text { High ST segment } \\
\text { usingmedical EKG }\end{array}$ & $\begin{array}{c}(T-S) \\
\left(T^{\prime}-S^{\prime}\right)\end{array}$ \\
\hline 1 & 314 & 369 & 55 & $2,5 \mathrm{~mm}$ & 22 \\
2 & 308 & 365 & 57 & $2,5 \mathrm{~mm}$ & 22,8 \\
3 & 298 & 364 & 66 & $3 \mathrm{~mm}$ & 22 \\
4 & 304 & 359 & 55 & $2,5 \mathrm{~mm}$ & 22 \\
\hline
\end{tabular}

Furthermore, the difference between $\mathrm{T}$ and $\mathrm{S}$ measured as the accuracy value is compared again to determine the accuracy point. This measurement was carried out on 10 different graphic packages from 10 people so that the following results were obtained. In this study, the authors involved an ICU nurse from Jakarta Siloam Hospital as an observer to determine whether the ECG graph used was feasible to be analyzed and had a level of similarity in plain sight. 
Table 2. ECG AD8232 output with the RST detection

\begin{tabular}{cccc}
\hline $\begin{array}{c}\text { People } \\
\text { ID }\end{array}$ & Similarity in form & $\begin{array}{c}\text { Similarity Percentage } \\
\text { Using T-S }\end{array}$ & Approved by Medical Practitioner \\
\hline 1 & Similar & $99 \%$ & Approved \\
2 & Similar & $97 \%$ & Approved \\
3 & Similar & $80 \%$ & Approved \\
4 & Similar & $88 \%$ & Approved \\
5 & Similar & $88 \%$ & Approved \\
6 & Similar & $65 \%$ & Rejected due to different measurement start \\
& & & point \\
7 & Similar & $90 \%$ & Approved \\
8 & Similar & $93 \%$ & Approved \\
9 & Similar & $93 \%$ & Approved \\
10 & Similar & $95 \%$ & Approved \\
\hline
\end{tabular}

It can be seen that in general, the form of the ECG AD8232 output with the RST detection proposed in this study has in common. One in ten samples were rejected because the time of the measurement starting point was different so it reduced objectivity in measurement

\section{CONCLUSION}

The purpose of the research has been achieved and the required function has been fulfilled in this paper. The system is able to determine $\mathrm{R}$ peak, measure $\mathrm{R}$ distance and detecting $\mathrm{S}-\mathrm{T}$ time. The system developed with the AD8232 module has similar results compared to medical standard ECG.

Further development is needed in advanced testing with patients in heart illness to gather variety ECG data. If possible, should be tested with a real case of heart attack (myocardial infarction) as well. Development can also be done by training the system to be able to detect other abnormalities so that the tool is able to function better.

\section{REFERENCES}

[1] Ary G., Zachary D., Alexei S., Goldberger's Clinical Electrocardiography - A Simplified Approach, Eighth Edition, Elsevier Saunders, 2013.

[2] Stephen W. Smith, et. al., "Diagnosis of ST-Elevation Myocardial Infarction in the Presence of Left Bundle Branch Block With the ST-Elevation to S- Wave Ration in a Modified Sgarbossa Rule", Annals of Emergency Medicine, Volume 60, No. 6, December 212.

[3] A. Peterkova, M. Stremy, "The raw ECG Signal Processing and The Detection of QRS Complex", 2015 IEEE European Modelling Sympoisum, 2015.

[4] American Heart Association, Asian \& Pacific Islanders and Cardiovascular Diseases, 2013

[5] Avvaru S., N. Sriraam, "An Engineering Perspective of External Cardiac Loop Recorder: A Systematic Review", Journal of Medical Engineering, Volume 2016.

[6] Kementerian Kesehatan RI, Data dan Informasi Kesehatan Penyakit Tidak Menular, Buletin Jendela, Semester II, 2012.

[7] M. Wildan Gifari, Hasballah Zakaria, R. Mengko, "Design of Homeracre: 12-Lead ECG Acquisition using Single Channel ECG Device Developed on AD8232 Analog Front End”, The 5th International Conference on Electrical Engineering and Informatics 2015, August 2015, Indonesia.

[8] Pavani L., Rama Koti, "Smart Detection and Transmission of Abnormalities in ECG Via Bluetooth", 2016 IEEE International Confrence on Smart Cloud.

[9] Kamrul Hussain, Sudden Impact Wearables Design Challenge : ECG Beat Rate [QRS Complex], April 2015.

[10] Dawoud F, Wagner GS, Moody G, Horacek BM. "Using inverse electrocardiography to image myocardial infarction--reflecting on the 2007 PhysioNet/Computers in Cardiology Challenge”. J Electocardiol 41(6):630-5 (2008 Nov-Dec).

[11] Goldberger AL, Amaral LAN, Glass L, Hausdorff JM, Ivanov PCh, Mark RG, Mietus JE, Moody GB, Peng C-K, Stanley HE. PhysioBank, PhysioToolkit, and PhysioNet: Components of a New Research Resource for Complex Physiologic Signals. Circulation 101(23):e215-e220 [Circulation Electronic Pages; http://circ.ahajournals.org/content/101/23/e215.full]; 2000 (June 13).

[12] http://www.ambulancetechnicianstudy.co.uk/rhythms.html\#.WTJBDGiGOiM 


\section{BIBLIOGRAPHY OF AUTHORS}

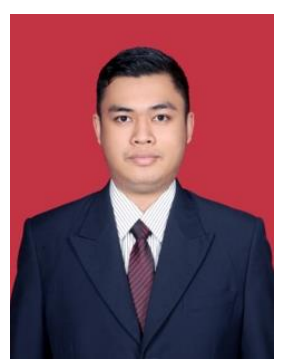

Martin Clinton Tosima Manullang was raised and borned in Medan. He is a lecturer in the Informatics Department, Institut Teknologi Sumatera. Completing a Masters degree at the Bandung Institute of Technology, he focused on researching in the field of intelligent systems including Internet of Things, Pervasive Computing, Fog Computing, and Smart City. During his spare time, he likes to play music and photography.

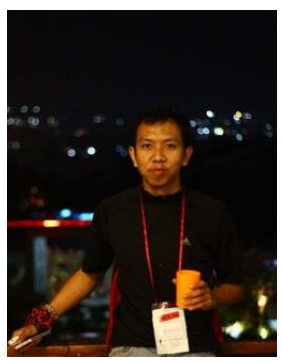

Jonathan Eprilio Soaduon Simanjuntak, currently is a student at Institut Teknologi Sumatera ITERA and currently in the stage of completing a final project that is still related to artificial intelligence in the detection of cardiac abnormalities. He is domiciled in Lampung. Jonathan has a musical hobby and enjoys playing saxophone in his free time.

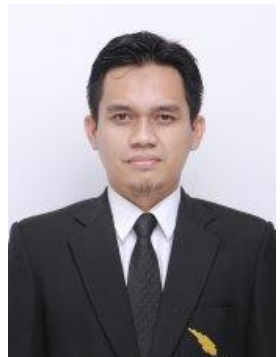

Ahmad Luky Ramdani is a lecturer at Institut Teknologi Sumatera and actively teaches in the fields of data mining, data warehouse, and web development. Luky completed his studies at IPB. Currently he also serves as co-founder of one of the sharia-based financial startups named ANGSUR.ID. 